\title{
A Proinflammatory Effect of the $\beta$-Glucan from Pleurotus cornucopiae Mushroom on Macrophage Action
}

\author{
Ken-ichiro Minato, ${ }^{1}$ Akihiro Ohara, ${ }^{1}$ and Masashi Mizuno ${ }^{2}$ \\ ${ }^{1}$ Department of Applied Biological Chemistry, The Graduate School of Agriculture, Meijo University, Nagoya 468-8502, Japan \\ ${ }^{2}$ Graduate School of Agricultural Science, Kobe University, Kobe 657-8501, Japan \\ Correspondence should be addressed to Ken-ichiro Minato; minato@meijo-u.ac.jp
}

Received 28 February 2017; Revised 17 April 2017; Accepted 19 April 2017; Published 22 May 2017

Academic Editor: Alex Kleinjan

Copyright (c) 2017 Ken-ichiro Minato et al. This is an open access article distributed under the Creative Commons Attribution License, which permits unrestricted use, distribution, and reproduction in any medium, provided the original work is properly cited.

\begin{abstract}
PCPS from P. citrinopileatus mushroom extract is a $\beta$-1,6-glucan possessing a proinflammatory effect on innate immune cells. The PCPS stimulated THP-1 macrophages to secrete significant levels of TNF. Moreover, the mRNA expressions of TNF and IL- $1 \beta$ were significantly enhanced by PCPS treatment. However, the PCPS did not induce to express both IL-12 and IL-10 mRNA in the macrophages. Next, the P. cornucopiae extract (containing mainly PCPS) treatment against mice showed significant increases in TNF and IL- $1 \beta$ mRNA expressions in the peritoneal macrophages of them. In this study, the expression levels of IFN $\gamma$ mRNA in the spleen were almost the same between the extract- (PCPS-) treated group and control group. However, the expression of IL-4 mRNA showed a lower level in the extract-treated group than that in the control. Our results suggested that the PCPS could induce proinflammatory action in the immune response. In addition, the proinflammatory effect of the PCPS on THP-1 was enhanced by 5 -GMP-Na, while it was reduced by vitamin $\mathrm{D}_{2}$. These two compounds are majorly contained in the $P$. citrinopileatus mushroom. Therefore, these results suggested that the $P$. citrinopileatus mushroom might contain other immune regulative compounds, such as vitamin $\mathrm{D}_{2}$, as well as PCPS.
\end{abstract}

\section{Introduction}

Many studies have suggested immunomodulating effects of edible and medicinal mushroom. A lot of edible mushrooms have become attractive as "functional foods" and as source materials for immunomodulators, antitumor agents, antibiotics, and antihypertensive drugs [1-3]. Emerging studies suggest that specific compounds, such as polysaccharides, from those mushrooms have potent and unique properties as biological response modifiers (BRM). For example, the glucans, which are Lentinan, purified from the fruiting body of Lentinus edodes, as well as Krestin, isolated from a medicinal mushroom, Trametes versicolor [4] and D-fraction, a glucan from the edible mushroom Grifola frondosa [5], display an antitumor activity [6]. It is considered that these polysaccharides from edible and medicinal mushrooms could augment or complement a desired immune system to maintain a health condition in a host. Furthermore, it is proposed that differences in immunomodulating properties which are observed are due to differences in composition, size, and branching of the glucans through the interaction with multiple, different cellular receptors. The basidiomycete, Pleurotus citrinopileatus, called "oyster mushroom" is one of popular edible mushrooms in Japan. The production and the consumption of $P$. citrinopileatus is increasing rapidly [7], which raises great interest in its proposed immunomodulating properties and identification of the underlying molecular mechanisms. Recently, we have shown that $P$. citrinopileatus possesses $\beta$-1,6-glucan with $\beta$-1,3-glucoside side chains that can activate human DCs via triggering of dectin-1 [8].

Due to many immunological reports, it has been considered that a macrophage can play a key role in our immunomodulating action. Macrophages are dynamic and heterogeneous cells. They express various pattern recognition receptors (PRRs), such as Toll-like receptors and Ctype lectins, and their interaction with a wide variety of different ligands leads to maturation, and/or modulation of the activation of macrophages, and the induction of 
specific adaptive immune responses [9-11]. PRR-activated macrophages will prime $\mathrm{T}$ cell responses. The macrophages initiate and regulate specific adaptive immune responses against various pathogens [12]. Moreover, it has been suggested that polarized macrophages are broadly classified into two types, M1 type and M2 type [13, 14]. Like Th1 lymphocytes, M1 is proinflammatory effectors and expresses mediators of inflammation such as IL-12, TNF, CC chemokines, and nitric oxide. In contrast, M2 macrophage plays an important role in immunoregulation system in which Th2 cytokines, such as IL-4 or IL-13 are involved. The monocytic THP-1 human myeloid leukemia cell line can be induced by phorbol 12-myristate 13-acetate (PMA) to differentiate into macrophage-like morphology [15]. Upon PMA treatment, the cells show an altered differentiation dependent on cell surface markers in a pattern similar to monocyte-derived macrophages [16]. In addition, they express a cytokine profile that resembles macrophages. We here set out to investigate the immune modulating properties of $P$. citrinopileatus glucan, PCPS, using macrophage-like cells derived from a THP-1 cell line, which are essential to regulate immune responses as well as DCs.

\section{Materials and Methods}

2.1. Reagent. Escherichia coli (0111:B4) LPS was purchased from Sigma-Aldrich (MO, USA). Human TNF mAb was purchased from R\&D Systems (Abingdon, U.K.). qPCR was performed by using SYBR ${ }^{\circledast}$ Premix EX Taq $^{\mathrm{TM}}$ II (Takara, Japan). 5'-GMP-Na and ergocalciferol (as vitamin $\mathrm{D}_{2}$ ) were purchased from Sigma-Aldrich (MO, USA).

2.2. Preparation of the Mushroom Extracts. The $450 \mathrm{kD}$ polysaccharide fraction of $P$. citrinopileatus was prepared from a hot water extract as described previously [7]. Shortly, a hot water extract (a crude glucan fraction) from the mushroom fruiting body was separated into six fractions by DEAESepharose chromatography. The active fraction was further purified by using a Sephacryl S-400 column, resulting in the active $450 \mathrm{kDa}$ polysaccharide named PCPS, which was dissolved in distilled $\mathrm{H}_{2} \mathrm{O}$. The amount of PCPS in the hot water extract was $735.4 \pm 43.5 \mu \mathrm{g} / \mathrm{mg}$ (as glucose, measured by anthrone-sulfuric acid method). To determine whether PCPS was endotoxin free, the polysaccharide was pretreated with polymyxin B $(10 \mu \mathrm{g} / \mathrm{ml}$, Sigma-Aldrich, MO, USA $)$ for 2 hours at $37^{\circ} \mathrm{C}$ prior to the priming.

2.3. Preparation of Macrophage Cell Line. The monocyte cellline, THP-1 (Riken BRC Cell Bank, Tsukuba, Japan) was cultured to confluence in RPMI1640 medium containing 10\% fetal bovine serum (FBS) and 1\% glutamate/penicillin/streptomycin (G/P/S). THP-1 cells were differentiated to macrophages as follows. Their macrophage-like states were obtained by treating each monocyte for $48 \mathrm{hrs}$ with $160 \mathrm{nM}$ of phorbol 12-myristate 13-acetate (PMA; Sigma) in 24well cell culture plates (Nunc) with cell suspension $\left(1 \times 10^{6}\right.$ cells). Then, differentiated and adherent cells were washed twice with RPMI 1640 medium containing 10\% FBS and
$1 \% \mathrm{G} / \mathrm{P} / \mathrm{S}$. And, to obtain the resting state of macrophage, they were rested for another $24 \mathrm{hr}$ in the culture medium. After incubation, the cultures were washed to remove the nonadherent cells, and then the tested sample in fresh medium was added to the plates and cultured for $24 \mathrm{hr}$ at $37^{\circ} \mathrm{C}$ and $5 \% \mathrm{CO}_{2}$. Then, the supernatant of cultures was collected and kept at $-80^{\circ} \mathrm{C}$ until a measurement of the cytokine production.

2.4. Determination of TNF Level Secreted by the Differentiated THP-1 Macrophage. The production of TNF by the differentiated THP-1 macrophages was determined by ELISA analysis of the cell-free supernatants after incubation of the THP-1 with different stimuli for 24 hours. TNF level was determined by using anti-TNF antibodies as previously described [17]. Briefly, a NUNC maxisorb 96-well plate was coated with coating $\mathrm{Ab}$ of each cytokine overnight at $4^{\circ} \mathrm{C}$. After blocking for $30 \mathrm{~min}$ at $37^{\circ} \mathrm{C}$, the supernatant of the culture and the detection $\mathrm{Ab}$ was added ( 2 hours, on an orbital shaker at $500 \mathrm{rpm}, \mathrm{RT})$. Simultaneously, cytokine concentration standards were tested. The plate was washed 4 times with PBS and incubated for $30 \mathrm{~min}$ with Streptavidin HRP. The reaction was developed by Tetramethylbenzidine (TMB) substrate, and optical density was measured by a spectrophotometer $(450 \mathrm{~nm})$.

2.5. The P. citrinopileatus Extract Treatment for the Mice. All animal experiments were performed in accordance with the guidelines of the Animal Care and Use Committee of Meijo University and were approved by the Committee. BALB/c mice (6-week-old, female) were purchased from Japan SLC Inc. (Shizuoka, Japan). The animals were housed in controlled conditions $\left(20-25^{\circ} \mathrm{C}, 50-55 \%\right.$ humidity, and a $12 \mathrm{~h}$ light/dark cycle) with free access to water and a standard rodent chow (AIN-76A, Research Diet Inc.). After acclimation for 7 days, the animals were randomly divided into 2 groups ( $n=5$ for each group): normal control (control), $P$. citrinopileatus extract (containing mainly PCPS) group $(680 \mu \mathrm{g} / \mathrm{kg}$ b.w. as $500 \mu \mathrm{g} / \mathrm{kg}$ based on PCPS). The experimental extracts dissolved in distilled water were orally administered every day for two weeks. Normal control mice were administered an equal volume of distilled water. Body weights were monitored every two days during the period. At necropsy, peritoneal cells and spleen were collected under inhalation anesthesia. Peritoneal cells were collected by repeated intraperitoneally wash of RPMI medium. Collected cells were washed with RPMI 1640 and then plated in 24-well culture plates at a density of $1 \times 10^{6}$ cells per well. Cultures were incubated for adhesion to plates for $2 \mathrm{hrs}$ at $37^{\circ} \mathrm{C}$ and $5 \% \mathrm{CO}_{2}$. After incubation, the cultures were washed to remove the nonadherent cells. Then fresh medium was added to the plates and cultured for $2 \mathrm{hrs}$ at $37^{\circ} \mathrm{C}$ and $5 \%$ $\mathrm{CO}_{2}$. After incubation, to measure cytokine mRNA level expressed in the macrophages, the cells were collected and then stored in RNAlater (Qiagen) at $-80^{\circ} \mathrm{C}$ until a measurement of cytokine mRNA expression. Spleen in each mouse was collected, immediately followed by addition of RNAlater. And then they were stored at $-80^{\circ} \mathrm{C}$ until a measurement of cytokine mRNA expression. 
TABLE 1: Oligonucleotide primers designed for human (h) or mouse (m) genes in quantitative real-time PCR.

\begin{tabular}{lcc}
\hline Gene & Forward $\left(5^{\prime}-3^{\prime}\right)$ & Reverse $\left(5^{\prime}-3^{\prime}\right)$ \\
\hline$h T N F$ & gaggccaagccctggtatg & cgggccgattgatctcagc \\
$h I L-1 b$ & atgatggcttattacagtggcaa & gtcggagattcgtagctgga \\
$h I L-10$ & gactttaagggttacctgggttg & tcacatgcgccttgatgtctg \\
$h I L-12 p 40$ & gcggagctgctacactctc & ccatgacctcaatgggcagac \\
$h G A P D H$ & acgacccttcattgacc & agacaccgatagactccacg \\
$m T N F$ & caggcggtgcctatgtctc & cgatcacccgaagttcagtag \\
$m I L-1 b$ & gaaatgccaccttttgacagtg & tggatgctctcatcaggacag \\
$m I L-4$ & ccccagctagttgtcatcctg & caagtgattttgtcgcatccg \\
$m I L-10$ & gtgaaaataagagcaaggcagtg & attcatggccttgtagacacc \\
$m I F N g$ & agcggctgactgaactcagattgtag & gtcacagttttcagctgtataggg \\
$m G A P D H$ & tcaacagcaactcccactcttcca & acctgttgctgtagccgtattca \\
\hline
\end{tabular}

2.6. Quantitative Real-Time PCR. The total RNA extractions from cultured frozen mouse spleen were performed by using RNAeasy ${ }^{\circledast}$ reagent (Qiagen) according to the manufacturer's protocol. And then cDNAs were synthesized from the total RNAs by reverse transcription by using PrimeScript ${ }^{\circledast}$ RT Master Mix (Takara, Japan) priming with random hexamer and oligo (dT), according to the manufacturer's instructions. Oligonucleotide primers (Table 1) were designed as described previously $[7,8]$ and purchased as commercially available products (STAR Oligo, Rikaken, Japan). Real-time PCR were performed with SYBR Green method as described previously using StepOne Plus ${ }^{\mathrm{TM}}$ Real-Time PCR System (ThermoFisher Scientific) [18]. Relative changes in mRNA expression between samples were determined using the comparative $\mathrm{Ct}$ method $(\Delta \Delta \mathrm{Ct})$.

2.7. Statistical Analysis. Results are expressed as the mean \pm S.E.M. Statistical analyses were performed using SPSS 24 software (IBM, USA). A one-way ANOVA was performed followed by the Dunnett's $t$-test, or Student's $t$-test was performed. The level of significance was stated in the figure legends.

\section{Results}

3.1. The PCPS Shows the Potential to Induce Proinflammatory Cytokine Secretion in the Differentiated THP-1. A $450 \mathrm{kD} P$. citrinopileatus polysaccharide (PCPS) was obtained from a hot water extract of the mushroom's fruiting bodies, followed by ethanol precipitation and purification steps as described previously [7]. It has been shown that the PCPS contains $\beta$ 1,6-glucopyranoside residues as (part of) the main chain by the observation of the ${ }^{13} \mathrm{C}$ NMR signal and suggested that $\beta$-1,3-branched glucopyranoside residues are attached to the main structure of PCPS [8]. To determine whether PCPS could activate macrophages, the differentiated macrophagelike cells, THP-1, by PMA-treatment were incubated with this glucan. PCPS stimulated the macrophages to secrete significant levels of the proinflammatory mediators TNF (Figures 1 and 2(a)). In addition, cytokine mRNA levels were determined in the differentiated THP-1 stimulated with

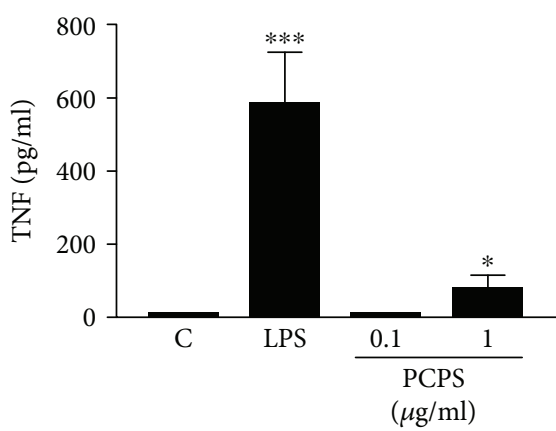

FIgURE 1: P. citrinopileatus polysaccharide PCPS induces secretion of proinflammatory cytokine, TNF, in THP-1 macrophages. Human monocyte cell line THP-1 was differentiated into macrophages by PMA $(160 \mathrm{nM})$ for $48 \mathrm{hrs}$., and then they were stimulated with the different concentrations of the $450 \mathrm{kD}$ polysaccharide (PCPS) purified from a hot water extract of $P$. citrinopileatus fruiting bodies, or LPS $(10 \mathrm{ng} / \mathrm{ml}$, as a positive control). After 24 hours, the secretion of TNF in the cell supernatant was determined by ELISA. The data shown are the average of 3 independent experiments. The depicted error bars represent the SEM of these 3 experiments. For statistical analysis, a one-way ANOVA followed by the Dunnett's $t$-test was used; ${ }^{*} p<0.05$ and ${ }^{* * *} p<0.001$ when compared to the RPMI medium control.

PCPS or LPS (as a positive control) for 2 hours (Figure 2). The mRNA expression levels of TNF (Figure 2(a)) and IL$1 \beta$ (Figure $2(\mathrm{~b})$ ) were significantly enhanced in the THP-1 stimulated with PCPS. However, PCPS stimulation did not induce secretions of both IL-12 (Figure 2(c)) and the antiinflammatory cytokine, IL-10, in the matured macrophages (Figure 2(d)). To exclude the contamination of endotoxin in the PCPS polymyxin B $(20 \mathrm{mg} / \mathrm{ml})$, an antibiotic that binds lipid A in LPS was included in the assays. Addition of polymyxin B in the assay did not affect the cytokine secretion stimulated by PCPS, although it could completely inhibit the LPS-induced production of TNF in the macrophages (data not shown). These results show that PCPS can activate matured macrophages to secrete proinflammatory cytokines, TNF, and IL- $1 \beta$, in the absence of an endotoxin, but not IL-12.

3.2. Effects of the Mushroom Extract on mRNA Expression of Macrophage Cytokine in Mice. The changes in body weights of the mice are presented in Figure 3. No significant change in the body weights was observed between both groups throughout the two-week feeding period. Peritoneal cells in the treated mice were collected after thioglycollate injection. The $P$. cornucopiae extract- (PCPS-) treated group showed significant increase in TNF and IL- $1 \beta$ mRNA levels in the attached cells compared to the normal control group (Figures 4(a) and 4(b)). However, IL-12 mRNA of the extract- (PCPS-) treated mice expressed at lower than that of control mice peritoneal cells (Figure 4(c)). Meanwhile, the extract treatment did not show a significant increase in the expression of IL-10 mRNA in the attached peritoneal cells (Figure 4(d)). These results suggested that the P. cornucopiae extract (PCPS) treatment predominantly showed the 


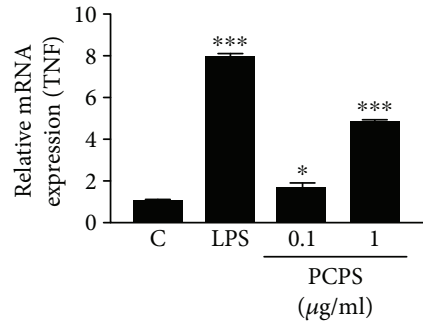

(a)

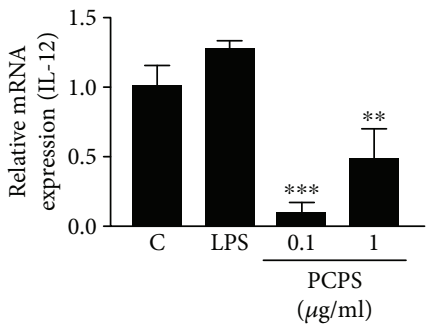

(c)

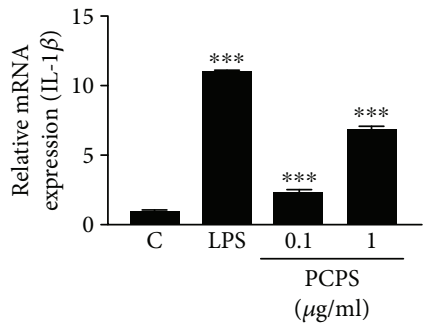

(b)

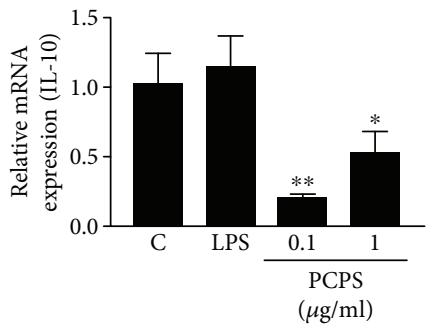

(d)

FIGURE 2: The P. citrinopileatus polysaccharide PCPS induces some proinflammatory cytokine expressions in THP-1. Human monocyte cell line THP-1 was differentiated into macrophages by PMA $(160 \mathrm{nM})$ for $48 \mathrm{hrs}$., and then they were stimulated with the different concentrations of the $450 \mathrm{kD}$ polysaccharide (PCPS) purified from a hot water extract of P. citrinopileatus fruiting bodies, or LPS $(10 \mathrm{ng} / \mathrm{ml}$, as a positive control). After 2 hours, the mRNA expression levels of TNF (a), IL-1 $\beta$ (b), IL-12 (c), and IL-10 (d) in the THP-1 were determined by using quantitative real-time PCR. Expression was determined relative to glyceraldehyde 3-phosphate dehydrogenase (GAPDH) and then each expression level was compared to the level of the RPMI medium control. The experiments shown are an average of 3 experiments. The depicted error bars represent the SEM of these 3 experiments. For statistical analysis, a one-way ANOVA followed by the Dunnett's $t$-test was used; ${ }^{*} p<0.05,{ }^{* *} p<0.01$, and ${ }^{* * *} p<0.001$ when compared to the RPMI medium control.

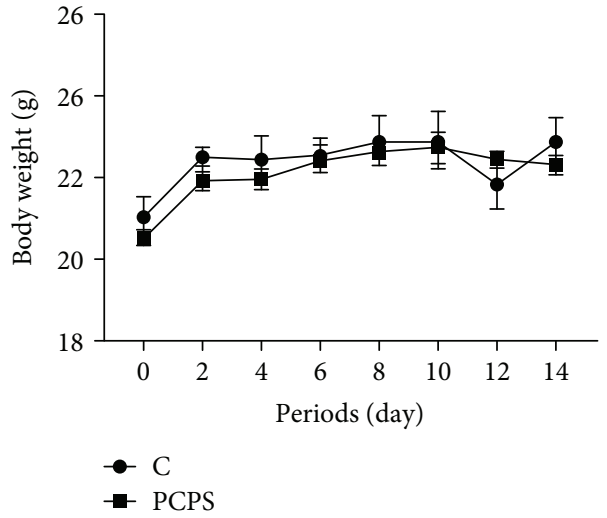

(a)

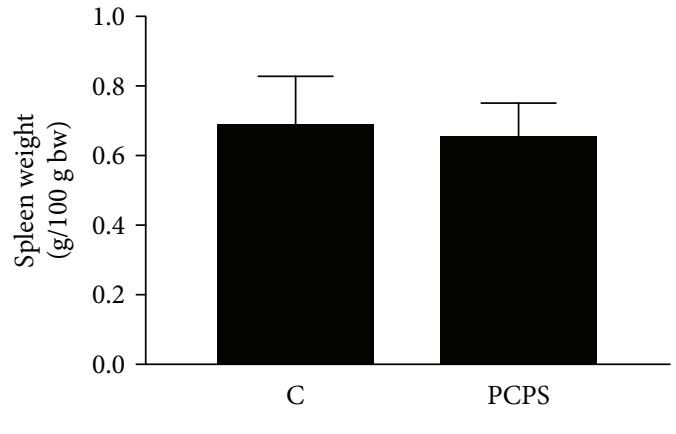

(b)

FIgURE 3: Effects of the P. citrinopileatus extract on body weights and relative spleen weights. The depicted error bars represent the SEM ( $n=5$ /group). After acclimation for 7 days, the animals were randomly divided into 2 groups ( $n=5$ for each group): normal control (C), P. citrinopileatus extract group (PCPS). The experimental extracts dissolved in distilled water were orally administered every day for two weeks. Normal control mice were administered an equal volume of distilled water. Body weights were monitored every two days during the period. Spleen weights were calculated as a proportion of body weight (g/100 g bw) at day 14 .

effect on proinflammatory action of immunocompetent cells in the peritoneal.

3.3. Effects of the Mushroom Extract on Cytokine mRNA Expressions in the Spleen of the Treated Mice. The change in spleen weights (calculated as a proportion of body weight) is also presented in Figure 3. No significant change in the spleen weights was observed between both groups during the feeding period. As shown in Figure 5(a), expression levels of IFN $\gamma$ mRNA in the spleen cells were almost the same between the $P$. cornucopiae extract- (PCPS-) treated mice group and control group. However, the expression of IL4, anti-inflammatory cytokine, mRNA showed a lower level in the spleen of the extract-treated group compared 


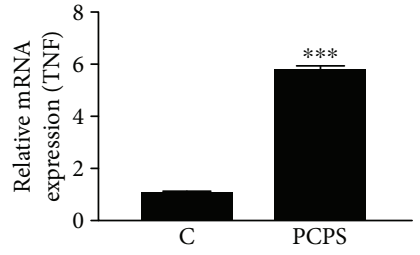

(a)

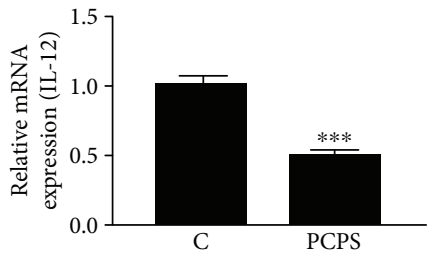

(c)

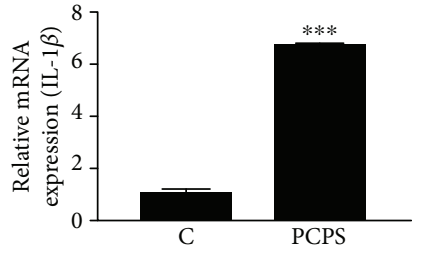

(b)

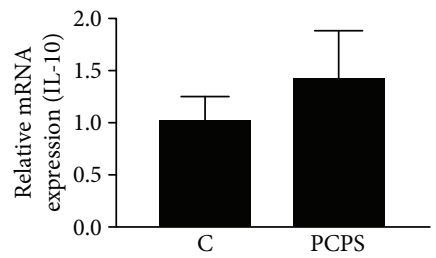

(d)

FIgURE 4: Effects of the P. citrinopileatus extract on cytokine expression in the mice peritoneal cells. After acclimation for 7 days, the animals were randomly divided into 2 groups ( $n=5$ for each group): normal control (C), P. citrinopileatus extract group (PCPS). The experimental extracts dissolved in distilled water were orally administered every day for two weeks. Normal control mice were administered an equal volume of distilled water. Peritoneal cells in the treated mice were collected after thioglycollate injection. After 2 hours incubation, the mRNA expression levels of TNF (a), IL-1 $\beta$ (b), IL-12 (c), and IL-10 (d) in the adherent cells from the peritoneal cells were determined by using quantitative real-time PCR. Expression was determined relative to glyceraldehyde 3-phosphate dehydrogenase (GAPDH), and then each expression level was compared to the level of the normal control group. The depicted error bars represent the SEM, and Student's $t$-test was used for the statistical analysis; ${ }^{* * *} p<0.001$ when compared to the normal control.

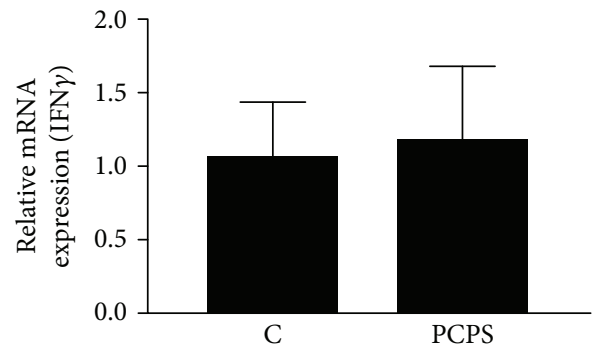

(a)

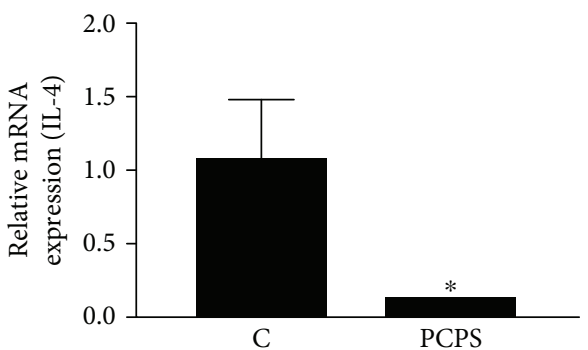

(b)

FIGURE 5: Influences of the P. citrinopileatus extract on cytokine expression in the mice spleen cells. After acclimation for 7 days, the animals were randomly divided into 2 groups ( $n=5$ for each group): normal control (C), P. citrinopileatus extract group (PCPS). The experimental extracts dissolved in distilled water were orally administered every day for two weeks. Normal control mice were administered an equal volume of distilled water. The mRNA expression levels of IFN $\gamma$ (a) and IL-4 (b) in the mice spleen cells were determined by using quantitative real-time PCR. Expression was determined relative to glyceraldehyde 3-phosphate dehydrogenase (GAPDH), and then each expression level was compared to the level of the normal control group. The depicted error bars represent the SEM, and Student's $t$-test was used for the statistical analysis; ${ }^{*} p<0.05$ when compared to the normal control.

to that of the normal control group (Figure 5(b)). Moreover, it was shown that the P. cornucopiae extract treatment (PCPS group) induced an increase in $\mathrm{CD}^{+} \mathrm{CD}^{+}$cell population in the spleen by using FACS analysis (data not shown). These results suggested that the PCPS might inhibit antiinflammatory action of the spleen lymphocyte.

\subsection{Combination Effect of Guanyl Acid/Vitamin $\mathrm{D}_{2}$ with} PCPS on Proinflammatory Cytokine Secretion from the Stimulated Macrophages. The proinflammatory effect of the PCPS on THP-1 activity was enhanced by 5 -GMP$\mathrm{Na}$ (Figure 6(a)), while it was reduced by vitamin $\mathrm{D}_{2}$ (Figure 6(b)). These results suggested that 5'-GMP-Na could upregulate PCPS-induced proinflammatory action; however, ergocalciferol would downregulate that.

\section{Discussion}

Various natural products have been used to treat and/or prevent many kinds of diseases, and the treatment of them has a long therapeutic history. Especially, natural $\beta$-glucans isolated from yeast, grain, and mushrooms are well-established biological response modifiers [19]. The glucans are highly conserved carbohydrates and possess a group of chemically heterogeneous polysaccharides polymerizing with various numbers of molecules of glucose bound together with several 


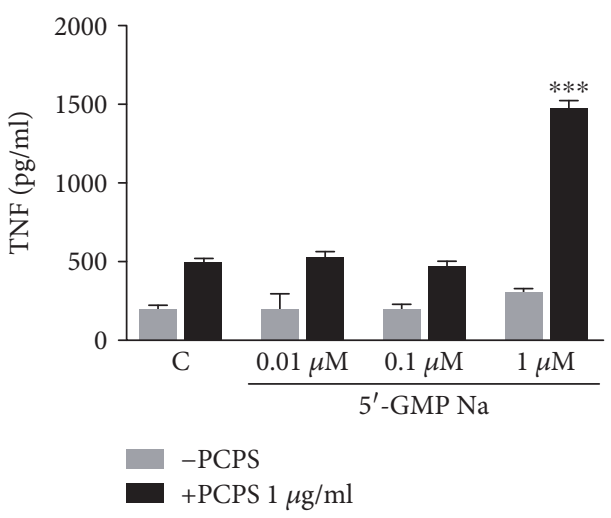

(a)

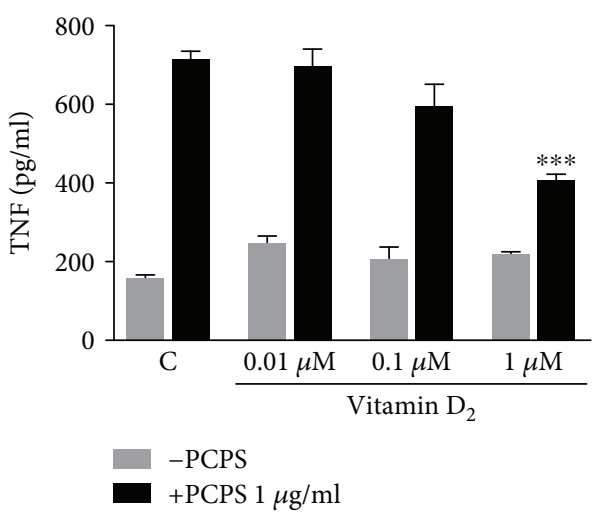

(b)

FIguRE 6: Combination effect of guanyl acid/vitamin $\mathrm{D}_{2}$ with PCPS on proinflammatory cytokines secretion from the stimulated macrophages THP-1. Human monocyte cell line THP-1 was differentiated into macrophages by PMA (160 nM) for $48 \mathrm{hrs}$., and then they were stimulated with $1 \mu \mathrm{g} / \mathrm{ml}$ of the $450 \mathrm{kD}$ polysaccharide (PCPS) purified from a hot water extract of P. citrinopileatus fruiting bodies plus the different concentrations of 5'-GMP-Na (Figure 6(a)) or ergocalciferol as vitamin $\mathrm{D}_{2}$ (Figure 6(b)). After 24 hours, the secretion of TNF in the cell supernatant was determined by ELISA. The data shown are the average of 3 independent experiments. The depicted error bars represent the SEM of these 3 experiments. For statistical analysis, a one-way ANOVA followed by the Dunnett's $t$-test was used; ${ }^{* * *} p<0.001$ when compared to the RPMI medium control.

types and degrees of branching. The glucan research began with showing its ability to stimulate the phagocytic system, enhance general defense mechanisms, and promote resistance to tumours. The effects of many glucans, which are able to activate macrophages, have been already reported, and their effects play an important role in the immune response [20-22]. $\beta$-glucans, such as lentinan and D-fraction, have shown to exert beneficial therapeutic effects against various diseases. Currently, several additional important effects of the glucans have demonstrated, including reduction of stress [23], hypoglycemic effects, reduction of cholesterol level [24], and improvements of ulcerative colitis [25]. Moreover, the glucans were found to significantly stimulate defense reactions against infections and cancer [26]. Furthermore, $\beta$-glucan administration could prevent/improve symptoms of allergic rhinitis and upper respiratory tract infections [27]. We previously isolated an immunomodulating $450 \mathrm{kDa}$ polysaccharide from the oyster mushroom P. citrinopileatus (PCPS) which was composed of glucose [7]. Our structural analysis of $P$. citrinopileatus PCPS suggested that PCPS most likely is a $\beta$-1,3-branched $\beta$-1,6-glucan [8]. Other reports demonstrate immunomodulating $\beta$-1,6-branched $\beta-1,3-\mathrm{D}$ glucan polysaccharides in Pleurotus mushrooms [28], suggesting that Oyster mushrooms contain different types of immunomodulating $\beta$-glucans.

We have already reported that PCPS can induce maturation of human immature DCs and the secretion and/or expression of many proinflammatory mediators, as well as the secretion of the anti-inflammatory cytokine IL-10 [8]. Our findings suggested that PCPS can induce activation of DCs, but may simultaneously suppress (over) production of proinflammatory mediators which may contribute to a balanced immune response in their hosts. Furthermore, we here showed that PCPS treatment could stimulate proinflammatory action of macrophage in vivo as well as in vitro (Figures 1, 2, and 4). Because it is generally considered that maintaining a balance of M1 and M2 macrophages could prevent from a development of an immune-deficient disease, such as inflammatory, allergy, and cancer, it is certainly expected that the immunomodulating polysaccharide could regulate this macrophage balance. In this study, we showed that PCPS possessed proinflammatory effect on macrophage action. However, our recent study focused on the influence of PCPS on action of innate immune system. Indeed, macrophages, which are widely distributed in a variety of organs [29], play important roles in regulating responses among each cell in an immune system [30]. Therefore, it remains unclear what kind of influence the PCPS treatment shows on action of lymphocytes in acquired immune system.

PRR-activated innate immune cells such as macrophages and DCs will prime T cell responses. Regarding macrophage, mirroring the Th1/Th2 polarization of $\mathrm{T}$ cells, polarized macrophages are often referred to as inflammatory (M1 or classically activated) and regulatory (M2 or alternatively activated) macrophages $[13,31]$. Inflammatory macrophages are involved in antimicrobial activities. In contrast, it has also been reported that regulatory macrophages promote tissue repair and contribute to metabolic homeostasis, and they are involved in immunity against parasitic helminth infections, through an acquired immune system [29, 32]. Moreover, regarding amelioration of allergic diseases, such as allergic rhinitis, asthma, and chronic atopic disorders, it is important to control the Th2 immune response [33, 34]. Therefore, it is important to examine whether immunomodulating agents such as $\beta$-glucan have influence on actions of lymphocytes such as $\mathrm{T}$ cell populations in acquired immune system, as well as that on macrophage action in innate immune system. In this study, it was shown that the $P$. cornucopiae extract treatment (PCPS group) induced an increase in $\mathrm{CD}^{+} \mathrm{CD}^{+}$cell (as helper T lymphocytes) population in the spleen. However, the population of $\mathrm{CD} 3^{+} \mathrm{CD} 8^{+}$ (as killer $\mathrm{T}$ lymphocytes) has not been affected by PCPS treatment in the spleen of the mice (data not shown). The PCPS treatment inhibited an expression of IL-4, an anti- 
inflammatory cytokine, mRNA in the lymphocytes of the mice spleen in this study. Meanwhile, interestingly, the glucan treatment did not show any influence on an expression of IFN $\gamma$ mRNA in the spleen, which is a proinflammatory cytokine (Figure 5). In the immune system, the cytokines IL-12, TNF, and IL-1 $\beta$ [35] are known as key effectors linked to host protection and secreted by both innate and acquired immune cells. Among them, IL-12 is critical for the induction of IFN $\gamma$ in a variety of immune cells as well as the activation of $\mathrm{CD}^{+} \mathrm{T}$ cells, leading to the protective Th1 response [36]. The proinflammatory effect of PCPS on IL-12 secretion was significantly weak in the mice peritoneal macrophages stimulated with PCPS, as well as in the THP-1 (Figure 4). Therefore, the secretion of IFN $\gamma$ might not enhance in the spleen cells of treated mice.

The mushroom contains many kinds of bioactive substances such as vitamin $\mathrm{D}_{2}$, nucleic acids, and amino acid as well as $\beta$-glucan. Some reports have shown that the effect of glucan was synergistically increased by combination dose of other substances. Therefore, in this study, we attended to assess the combination effect of PCPS and some substances contained in P. citrinopileatus mushroom. The effect of the PCPS on proinflammatory action of macrophage was enhanced by $5^{\prime}$-GMP-Na, while it was reduced by vitamin $\mathrm{D}_{2}$ treatment (Figure 6). It has been known that both $5^{\prime}$-GMP-Na and vitamin $\mathrm{D}_{2}$, ergocalciferol, are major substances in the mushrooms. These compounds, in our study, might affect the proinflammatory effect of single PCPS in systemic immune response. In this study, combination dose of PCPS with 5'-GMP-Na/vitamin $\mathrm{D}_{2}$ showed to affect proinflammatory action of macrophages such as TNF secretion. Therefore, our results suggested that the P. citrinopileatus $\beta$-glucan could regulate macrophage activities, and the mushroom might contain other immune regulative compounds, such as vitamin $D_{2}$, for prevention from excess proinflammatory activities.

By the way, we have showed that the signalling pathways via not only dectin-1 but also TLRs play major roles in the PCPS-mediated immune response, suggesting PCPS has the capacity to activate human DCs via multiple pathways [8]. Several studies have demonstrated that the cross-talk between dectin- 1 and TLRs is required for activation of $\mathrm{NF}-\kappa \mathrm{B}$ and production of inflammatory cytokines in monocytes, DCs, and macrophages $[37,38]$, suggesting that collaboration between dectin-1 and the TLRs might play an important role in inflammatory responses to fungus polysaccharide. Interestingly, PCPS could also induce secretion of the anti-inflammatory cytokine, IL-10, in DCs [8]. And, the effect of PCPS on innate immune cells and on acquired immune cells, in this study, was not consistent with each other. Detailed studies of single treatment of the $P$. citrinopileatus polysaccharide PCPS will be necessary to completely understand how this polysaccharide modulates the immune response.

\section{Conclusion}

The P. citrinopileatus polysaccharide PCPS has been identified as a $\beta$-glucan which activates macrophage cells by upregulation of the secretion or expression of many proinflammatory mediators. It has been shown that the PCPS from $P$. citrinopileatus extract contains $\beta$-1,6-glucopyranoside residues as (part of) the main chain with $\beta$-1,3-branched glucopyranoside residues. PCPS from $P$. citrinopileatus mushroom extract is a $\beta$-1,6-glucan possessing a proinflammatory effect on innate immune cells. The PCPS stimulated THP-1 macrophages to secrete significant levels of TNF. Moreover, the mRNA expressions of TNF and IL$1 \beta$ were significantly enhanced by PCPS treatment. However, the PCPS did not induce to express both IL-12 and IL-10 mRNA in the macrophages. Next, the P. cornucopiae extract (containing mainly PCPS) treatment against mice showed significant increases in TNF and IL- $1 \beta$ mRNA expressions in the peritoneal macrophages of them. These results suggested that the PCPS could induce proinflammatory action in an innate immune response. Meanwhile, the expression of IL-4 mRNA showed a lower level in the extract-treated group than that in the control. However, the expression levels of IFN $\gamma$ mRNA in the spleen cells were almost the same between the extract- (PCPS-) treated group and control group. Further studies of the effect of $P$. citrinopileatus polysaccharide PCPS on those cytokine expressions will be necessary to completely understand how this polysaccharide modulates the immune response between IL- 4 and IFN $\gamma$. In addition, the proinflammatory effect of the PCPS on THP-1 was enhanced by 5 -GMP-Na, while it was reduced by vitamin $\mathrm{D}_{2}$. These two compounds are majorly contained in the $P$. citrinopileatus mushroom. Therefore, our results suggested that the $P$. citrinopileatus mushroom could regulate macrophage activities by its $\beta$-glucan and might contain other immune regulative compounds, such as vitamin $\mathrm{D}_{2}$, as well as PCPS.

\section{Conflicts of Interest}

The authors declare that they have no conflicts of interest.

\section{Acknowledgments}

The authors thank Kinokkusu Co., Japan, for the gift of fruiting bodies of $P$. citrinopileatus. This work was supported by JSPS KAKENHI Grant no. 26560070.

\section{References}

[1] X. Q. Han, B. Chung Lap Chan, C. X. Dong et al., "Isolation, structure characterization, and immunomodulating activity of a hyperbranched polysaccharide from the fruiting bodies of Ganoderma sinense," Journal of Agricultural and Food Chemistry, vol. 60, no. 17, pp. 4276-4281, 2012.

[2] S. Zhang, S. Nie, D. Huang, J. Huang, Y. Wang, and M. Xie, "Polysaccharide from Ganoderma atrum evokes antitumor activity via toll-like receptor 4-mediated NF-kappaB and mitogen-activated protein kinase signaling pathways," Journal of Agricultural and Food Chemistry, vol. 61, no. 15, pp. 36763682, 2013.

[3] C. Kerekgyarto, L. Virag, L. Tanko, G. Chihara, and J. Fachet, "Strain differences in the cytotoxic activity and TNF production of murine macrophages stimulated by lentinan," 
International Journal of Immunopharmacology, vol. 18, no. 67, pp. 347-353, 1996.

[4] K. Quayle, C. Coy, L. Standish, and H. Lu, "The TLR2 agonist in polysaccharide- $\mathrm{K}$ is a structurally distinct lipid which acts synergistically with the protein-bound beta-glucan," Journal of Natural Medicines, vol. 69, no. 2, pp. 198-208, 2015.

[5] Y. Masuda, H. Inoue, H. Ohta, A. Miyake, M. Konishi, and H. Nanba, "Oral administration of soluble beta-glucans extracted from Grifola frondosa induces systemic antitumor immune response and decreases immunosuppression in tumor-bearing mice," International Journal of Cancer, vol. 133, no. 1, pp. 108-119, 2013.

[6] T. Sasaki and N. Takasuka, "Further study of the structure of lentinan, an anti-tumor polysaccharide from Lentinus edodes," Carbohydrate Research, vol. 47, no. 1, pp. 99-104, 1976.

[7] K. Minato, "Immunomodulation activity of a polysaccharide fraction of a culinary-medicinal mushroom, Pleurotus citrinopileatus singer (Agaricomycetideae), in vitro," International Journal of Medicinal Mushrooms, vol. 10, no. 3, pp. 235-244, 2008.

[8] K. I. Minato, L. C. Laan, A. Ohara, and I. van Die, "Pleurotus citrinopileatus polysaccharide induces activation of human dendritic cells through multiple pathways," International Immunopharmacology, vol. 40, pp. 156-163, 2016.

[9] D. M. Underhill and A. Ozinsky, "Toll-like receptors: key mediators of microbe detection," Current Opinion in Immunology, vol. 14, no. 1, pp. 103-110, 2002.

[10] S. Akira, K. Takeda, and T. Kaisho, "Toll-like receptors: critical proteins linking innate and acquired immunity," Nature Immunology, vol. 2, no. 8, pp. 675-680, 2001.

[11] S. J. van Vliet, J. den Dunnen, S. I. Gringhuis, T. B. Geijtenbeek, and Y. van Kooyk, "Innate signaling and regulation of dendritic cell immunity," Current Opinion in Immunology, vol. 19, no. 4, pp. 435-440, 2007.

[12] J. Banchereau and R. M. Steinman, "Dendritic cells and the control of immunity," Nature, vol. 392, no. 6673, pp. 245-252, 1998.

[13] M. Benoit, B. Desnues, and J. L. Mege, "Macrophage polarization in bacterial infections," Journal of Immunology, vol. 181, no. 6, pp. 3733-3739, 2008.

[14] O. Takeuch and S. Akira, "Epigenetic control of macrophage polarization," European Journal of Immunology, vol. 41, no. 9, pp. 2490-2493, 2011.

[15] T. Kohro, T. Tanaka, T. Murakami et al., “A comparison of differences in the gene expression profiles of phorbol 12myristate 13-acetate differentiated THP-1 cells and human monocyte-derived macrophage," Journal of Atherosclerosis and Thrombosis, vol. 11, no. 2, pp. 88-97, 2004.

[16] M. Daigneault, J. A. Preston, H. M. Marriott, M. K. Whyte, and D. H. Dockrell, "The identification of markers of macrophage differentiation in PMA-stimulated THP-1 cells and monocyte-derived macrophages," PloS One, vol. 5, no. 1, article e8668, 2010.

[17] C. M. van Stijn, S. Meyer, M. van den Broek et al., "Schistosoma mansoni worm glycolipids induce an inflammatory phenotype in human dendritic cells by cooperation of TLR4 and DCSIGN," Molecular Immunology, vol. 47, no. 7-8, pp. 15441552, 2010.

[18] E. J. Klaver, L. M. Kuijk, L. C. Laan et al., "Trichuris suisinduced modulation of human dendritic cell function is glycan-mediated," International Journal for Parasitology, vol. 43, no. 3-4, pp. 191-200, 2013.

[19] V. Vetvicka and J. Vetvickova, "Immune-enhancing effects of Maitake (Grifola frondosa) and shiitake (Lentinula edodes) extracts," Annals of Translational Medicine, vol. 2, no. 2, p. 14, 2014.

[20] S. Z. Xie, R. Hao, X. Q. Zha, L. H. Pan, J. Liu, and J. P. Luo, "Polysaccharide of Dendrobium huoshanense activates macrophages via toll-like receptor 4-mediated signaling pathways," Carbohydrate Polymers, vol. 146, pp. 292-300, 2016.

[21] Z. Liu, J. Xing, Y. Huang et al., "Activation effect of Ganoderma lucidum polysaccharides liposomes on murine peritoneal macrophages," International Journal of Biological Macromolecules, vol. 82, pp. 973-978, 2016.

[22] V. C. Castro-Alves, D. Gomes, N. Menolli Jr., M. L. Sforca, and J. R. Nascimento, "Characterization and immunomodulatory effects of glucans from Pleurotus albidus, a promising species of mushroom for farming and biomass production," International Journal of Biological Macromolecules, vol. 95, pp. 215-223, 2017.

[23] V. Vetvicka and J. Vetvickova, "Immune enhancing effects of WB365, a novel combination of Ashwagandha (Withania somnifera) and Maitake (Grifola frondosa) extracts," North American Journal of Medical Sciences, vol. 3, no. 7, pp. 320324, 2011.

[24] S. Rahar, G. Swami, N. Nagpal, M. A. Nagpal, and G. S. Singh, "Preparation, characterization, and biological properties of beta-glucans," Journal of Advanced Pharmaceutical Technology \& Research, vol. 2, no. 2, pp. 94-103, 2011.

[25] I. Lavi, D. Levinson, I. Peri, L. Nimri, Y. Hadar, and B. Schwartz, "Orally administered glucans from the edible mushroom Pleurotus pulmonarius reduce acute inflammation in dextran sulfate sodium-induced experimental colitis," The British Journal of Nutrition, vol. 103, no. 3, pp. 393-402, 2010.

[26] M. Novak and V. Vetvicka, "Glucans as biological response modifiers," Endocrine, Metabolic \& Immune Disorders Drug Targets, vol. 9, no. 1, pp. 67-75, 2009.

[27] R. Fuller, H. Butt, P. S. Noakes, J. Kenyon, T. S. Yam, and P. C. Calder, "Influence of yeast-derived 1,3/1,6 glucopolysaccharide on circulating cytokines and chemokines with respect to upper respiratory tract infections," Nutrition, vol. 28 , no. 6, pp. 665-669, 2012.

[28] R. Dobsikova, J. Blahova, I. Mikulikova et al., "The effect of oyster mushroom beta-1.3/1.6-D-glucan and oxytetracycline antibiotic on biometrical, haematological, biochemical, and immunological indices, and histopathological changes in common carp (Cyprinus carpio L.)," Fish \& Shellfish Immunology, vol. 35, no. 6, pp. 1813-1823, 2013.

[29] P. J. Murray and T. A. Wynn, "Protective and pathogenic functions of macrophage subsets," Nature Reviews. Immunology, vol. 11, no. 11, pp. 723-737, 2011.

[30] S. Gordon and P. R. Taylor, "Monocyte and macrophage heterogeneity," Nature Reviews. Immunology, vol. 5, no. 12, pp. 953-964, 2005.

[31] H. Suzuki, T. Hisamatsu, S. Chiba et al., "Glycolytic pathway affects differentiation of human monocytes to regulatory macrophages,” Immunology Letters, vol. 176, pp. 18-27, 2016.

[32] I. van Die and R. D. Cummings, "Glycan gimmickry by parasitic helminths: a strategy for modulating the host immune response?" Glycobiology, vol. 20, no. 1, pp. 2-12, 2010. 
[33] N. Kamada, T. Hisamatsu, S. Okamoto et al., "Abnormally differentiated subsets of intestinal macrophage play a key role in Th1-dominant chronic colitis through excess production of IL-12 and IL-23 in response to bacteria," Journal of Immunology, vol. 175, no. 10, pp. 6900-6908, 2005.

[34] F. A. Verreck, T. de Boer, D. M. Langenberg, L. van der Zanden, and T. H. Ottenhoff, "Phenotypic and functional profiling of human proinflammatory type-1 and antiinflammatory type- 2 macrophages in response to microbial antigens and IFN-gamma- and CD40L-mediated costimulation," Journal of Leukocyte Biology, vol. 79, no. 2, pp. 285293, 2006.

[35] A. M. Cooper, "Cell-mediated immune responses in tuberculosis," Annual Review of Immunology, vol. 27, pp. 393-422, 2009.

[36] A. M. Cooper, J. Magram, J. Ferrante, and I. M. Orme, "Interleukin 12 (IL-12) is crucial to the development of protective immunity in mice intravenously infected with mycobacterium tuberculosis," The Journal of Experimental Medicine, vol. 186, no. 1, pp. 39-45, 1997.

[37] G. D. Brown, P. R. Taylor, D. M. Reid et al., "Dectin-1 is a major beta-glucan receptor on macrophages," The Journal of Experimental Medicine, vol. 196, no. 3, pp. 407-412, 2002.

[38] M. S. Lee and Y. J. Kim, "Signaling pathways downstream of pattern-recognition receptors and their cross talk," Annual Review of Biochemistry, vol. 76, pp. 447-480, 2007. 


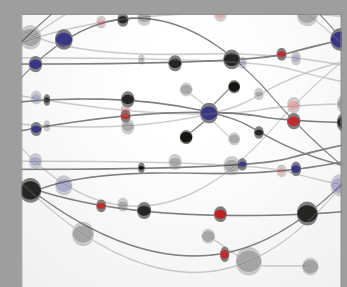

The Scientific World Journal
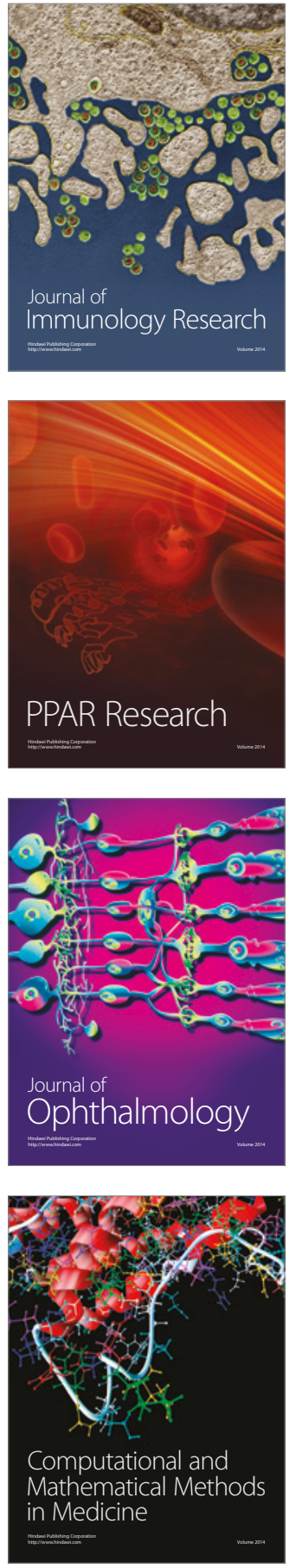

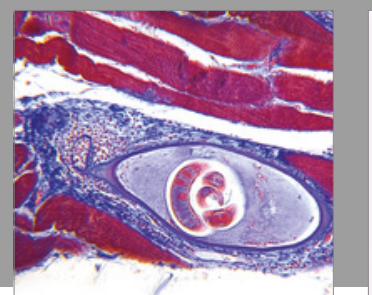

Gastroenterology Research and Practice
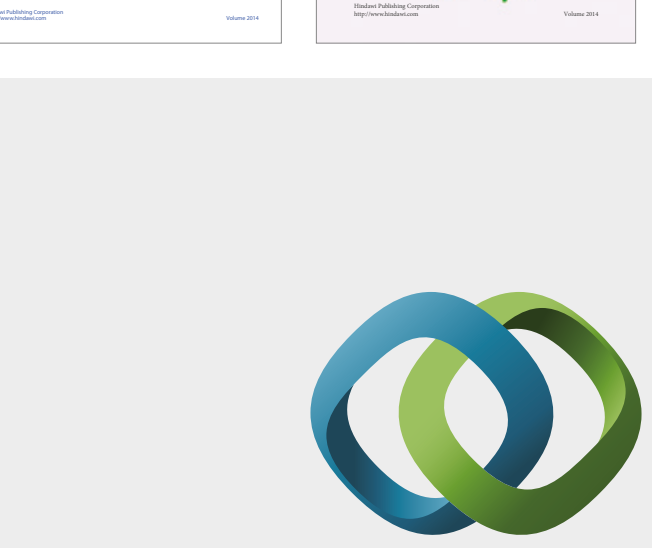

\section{Hindawi}

Submit your manuscripts at

https://www.hindawi.com
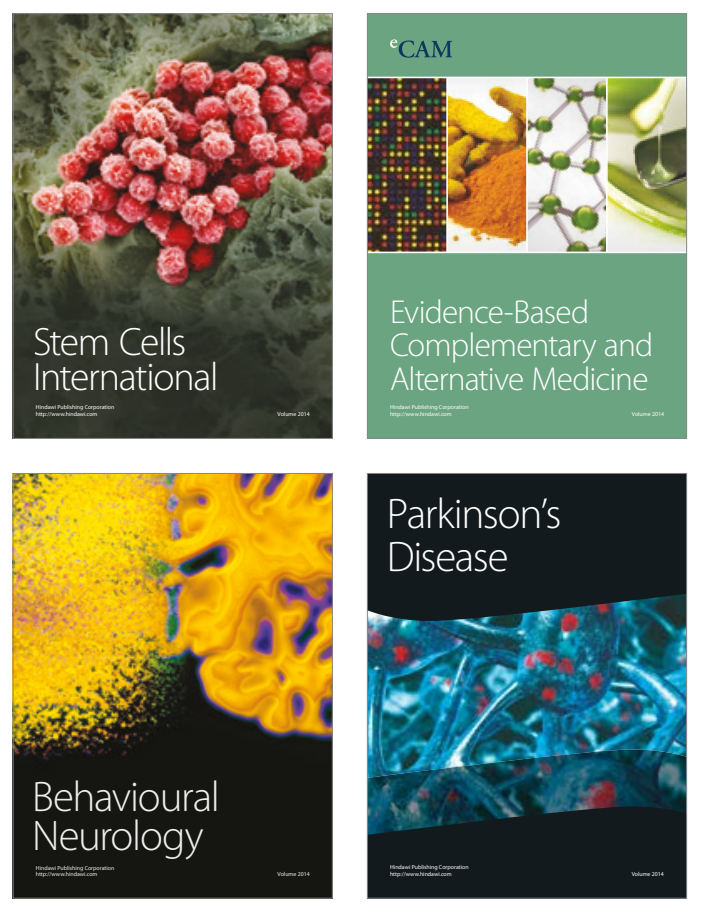
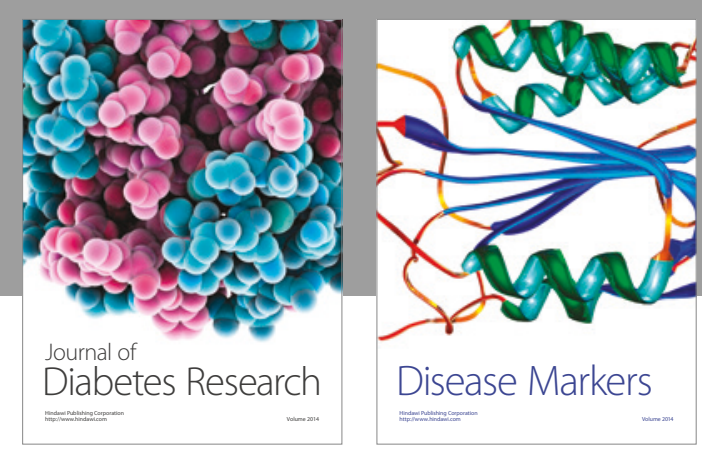

Disease Markers
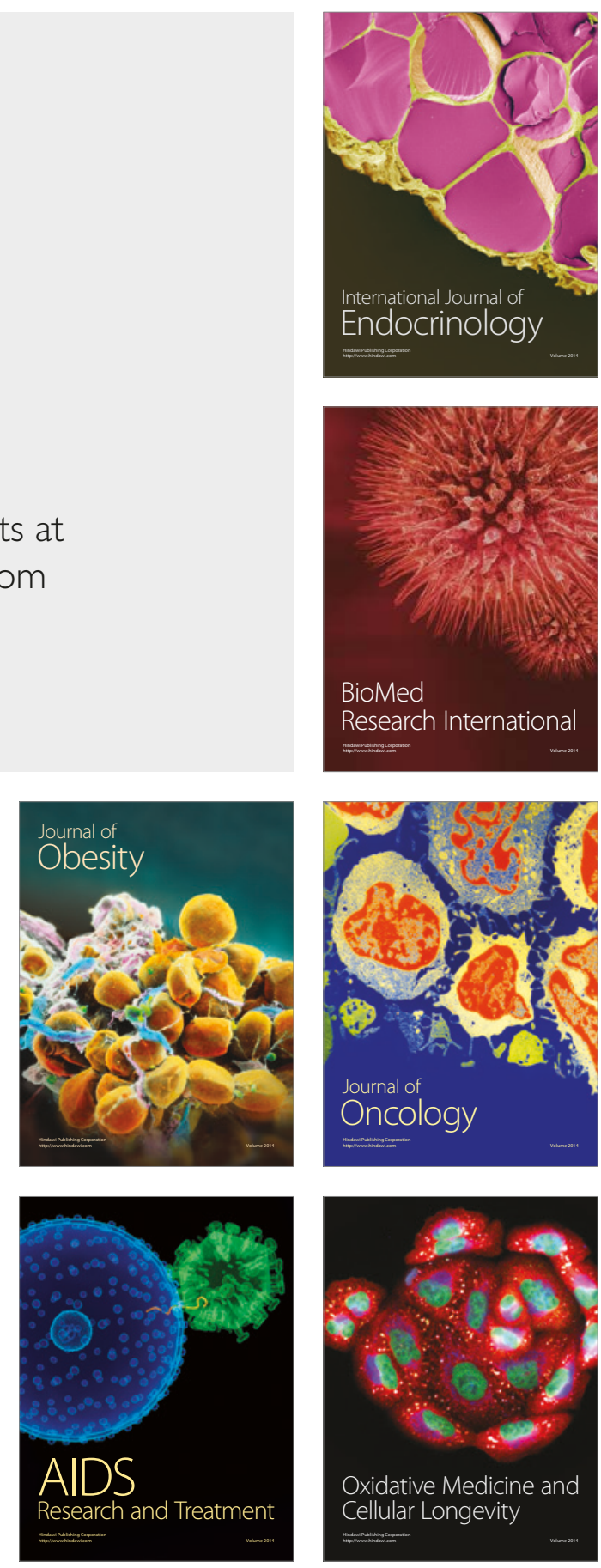